\title{
A EDUCAÇÃO BRASILEIRA NA PRIMEIRA ONDA LAICA: DO IMPÉRIO A REPÚBLICA
}

\section{THE BRAZILIAN EDUCATION IN THE FIRST LAY WAVE: FROM THE EMPIRE TO THE REPUBLIC.}

José Antonio Miranda Sepulveda ${ }^{\mathrm{i}}$

CUNHA, Luiz Antônio. A Educação Brasileira na Primeira Onda Laica: do império a república. Rio de Janeiro: Edição do Autor, 2017.

O professor Luiz Antonio Cunha sempre se destacou pela qualidade e pelo rigor de seu trabalho científico. E tal qualidade se manteve em seu último livro A Educação Brasileira na Primeira Onda Laica: do Império à República. Nesse, o autor se dispôs a analisar a polêmica temática da laicidade do Estado e da educação brasileira a partir de uma perspectiva histórica de longa duração, com o intuito de provocar no leitor uma necessidade de se atentar mais para o problema da laicidade no Brasil.

Ressalto ainda a generosidade do autor, não só pelo conteúdo e pelas referências examinadas e disponibilizadas no texto, mas também pelo fato de esse material ter sido veiculado gratuitamente pela Rede Mundial de Computadores ${ }^{\mathrm{ii}}$.

Este é um trabalho de fôlego. O autor analisa com muita precisão, desde o período que antecede a independência do Brasil, os debates feitos por diferentes atores políticos acerca da laicidade. Observa-se uma concentração maior de análise no período que vai da segunda metade do século XIX à Proclamação da República, abarcando ainda seus desdobramentos na Primeira República. Vale destacar que a grande novidade deste trabalho não está somente no tema, mas também na sua metodologia, estruturada a partir do conceito de campo de Pierre Bourdieu.

Outro destaque importante foi o cuidado de Cunha com os conceitos utilizados. O autor possibilita ao leitor entender o significado de alguns termos que são usados de forma confusa no senso comum e o faz explicitando que tais conceitos estavam e estão em disputa por diferentes forças do cenário político brasileiro.

Com efeito, o livro é muito cuidadoso na análise dos debates políticos, tanto no espectro da macropolítica, quanto no cotidiano das instituições educacionais. Isso porque o autor não privilegiou somente os atores e as instituições que protagonizaram o poder político do período 
em destaque, mas também procurou analisar como tal disputa se dava nas relações interpessoais. Enfatizo aqui a fantástica história do professor de origem alemã que lecionou na faculdade de Direito de São Paulo, Júlio Frank, apresentada pelo autor neste livro.

O livro está dividido em oito partes. Na primeira, intitulada Simbiose Estado-Igreja Católica, o autor discute o regime de padroado em um importante momento de crise da história política portuguesa: a fuga da Corte Portuguesa para o Brasil e a assinatura dos acordos internacionais com a Inglaterra em 1810. Por ser esse último um país não católico, foram necessárias, por parte do governo português, medidas de flexibilização do regime de padroado. Com isso, o autor destaca que, mesmo antes, e logo após a independência do Brasil, as forças políticas que se organizaram flertaram com a laicidade do Estado.

Na segunda parte do livro, intitulada Escravidão, Religião e Educação, o autor explora os pilares de organização do Estado brasileiro e os mecanismos constituídos através da educação de controle e da perpetuação da religião católica, oficial na sociedade brasileira. Sendo assim, escravidão e religião se tornaram os objetos de análise desta seção. Cunha analisa a complexa e paradoxal organização do campo religioso brasileiro, que se estruturou subjugada por agentes do campo político. Destaque importante desta seção foi o cuidado do autor em debater, com uma importante e atualizada bibliografia, as complexas relações existentes entre escravidão e educação no Brasil. Vale destacar também a organização peculiar que a educação brasileira acabou adotando com relação ao ensino: escolas confessionais e faculdades quase laicas.

Com o título de Avanço pelo Conflito, a parte três do livro se dedica a pontuar o crescimento da laicidade, de forma lenta, porém decisiva. $\mathrm{O}$ autor se debruça na análise da tensão constituída entre a igreja brasileira, submetida ao imperador e o processo de romanização inaugurado pela Santa Sé, intensificada no Brasil no último quartel do século XIX. O tensionamento em questão gerou um conflito entre a Igreja e o Estado, culminando na prisão dos bispos de Olinda e do Pará, respectivamente D. Vital e D. Macedo. O destaque dessa seção é a forma como Cunha trabalhou a configuração das principais forças políticas que se posicionaram a favor da laicidade do Estado, principalmente na educação laica: Maçons, Liberais, Positivistas e Protestantes. A importância que destaco nesta seção é a convincente análise acerca da fragilidade dessas configurações políticas cujas diferenças são marcadas por detalhes que impedem a unificação dessas forças políticas pró-laicidade.

A quarta parte do livro é em si um destaque no conjunto do texto. Nesta seção intitulada Educação Laica versus Confessional, o autor apresenta uma importante análise da discussão da laicidade, mais particularmente da escola laica, na intelectualidade brasileira. Partindo de uma precisa definição de intelectual, Cunha seleciona alguns intelectuais que se destacaram no Revista Interinstitucional Artes de Educar. Rio de Janeiro, V. 4 N. 2 - pag 450-453 (mai - ago 2018): "Dossiê 50 anos da Pedagogia do Oprimido: movimentos de opressões e emancipações contemporâneas na América Latina e África" DOI:10.12957/riae.2018.38037 
período, não só pela sua participação no campo político, mas também pela ampla divulgação de suas ideias na sociedade. São eles: Liberato Barroso, Júlio Koeller, Fritz Müller, Leôncio de Carvalho, Rui Barbosa, Inglês de Souza e Pires de Almeida. Cada um desses intelectuais defendeu uma posição destacada frente ao ensino religioso e a laicidade da escola. Destaco ainda a importante análise do autor referente ao processo de migração estrangeira para o Brasil para servir de mão de obra, trazendo consigo diferentes marcas identitárias, especialmente religiosa. Com isso, Cunha faz uma interessante avaliação da situação do Rio Grande do Sul e a forte concorrência da cultura alemã.

Na quinta parte intitulada Vetores da Secularização, o autor se preocupou com o processo de secularização da sociedade e tentou identificar os principais vetores de difusão de tal processo. Dessa forma, o livro apresenta alguns protagonistas que difundiram na cultura ideais seculares. O primeiro protagonista é o próprio imperador D. Pedro II, conhecido por ser muito estudioso e pelo seu amplo interesse pelas ciências. Mestres e professores também fazem parte de um importante vetor, principalmente pela forte presença de positivistas nessas profissões. Todavia, o destaque especial feito por Cunha é a imprensa, principalmente na difusão de ideias pró-laicidade. Tal difusão se deu em especial pelos chargistas. Vale também mencionar o aumento do número de praticantes de religiões protestantes que viam na secularização e laicização uma forma de garantir a sua própria liberdade de culto. Por fim, não se pode esquecer o papel da maçonaria na secularização da sociedade, muito bem explicitado pelo autor nesta seção.

A Laicidade Republicana em Construção é o título da sexta parte do livro. O destaque principal desta seção é o profundo estudo que o autor faz da presença do positivismo e da maçonaria no cenário político republicano. A proclamação da república brasileira trouxe a laicidade na educação consigo, tendo sido, segundo o autor, o único momento em que o ensino religioso não fez parte da legislação educacional brasileira. As mudanças na educação, com Benjamin Constant à frente no primeiro governo republicano, impôs uma nova realidade, que, apesar de não ter tido abrangência nacional, surtiu algum efeito na organização das escolas públicas, principalmente por ter se constituído enquanto proposta de educação em constante processo de reforma, tendo o modelo positivista como referência para o bem e para o mal. Cunha fez também uma importante análise da reação da Igreja Católica no período da primeira república, apontando para a crítica feita por essa instituição ao fim do ensino religioso nas escolas públicas. O autor termina a seção fazendo uma análise comparada da situação da laicidade brasileira e do ensino religioso com outros países ocidentais, em especial os países da América Latina. 
A sétima parte do livro é a onda da laicidade estourando na areia e o imediato recuo das águas para a posição de calmaria. Intitulado Laicidade Republicana em Desmanche, essa seção aborda o caráter contraditório da Proclamação da República no Brasil, uma vez que tal fato não foi suficiente para garantir a estruturação da laicidade no país. O autor destaca que a Igreja Católica, assim como as protestantes, acabou se beneficiando com a república, tanto na garantia de interesses políticos, como no caso de Canudos, como pela possibilidade de a Igreja negociar diretamente com os poderes locais, garantindo inclusive subsídios para a instalação de instituições privadas confessionais de ensino. O fim do regime de Padroado permitiu alguma liberdade para a Igreja, que culminou no aumento do número de fiéis e de intelectuais católicos leigos e consequentemente no retorno, de forma progressiva e efetiva, do Ensino Religioso nas escolas públicas brasileiras, principalmente a partir da Constituição de 1934.

A última parte do livro intitulada Ondas Divergentes, funciona como uma espécie de conclusão do livro. Nesta seção, o autor avalia os diferentes momentos pelo qual passou a laicidade no Brasil, apontando para semelhanças temporais com outras ondas de laicidade no mundo, e, principalmente com a ampliação do leque religioso no Brasil do século XX. Apesar da hegemonia católica, outras religiões se destacaram na luta por uma escola pública laica, marcando assim uma posição que confirma uma onda laica no Brasil, a partir, principalmente, da segunda metade do século XIX.

Por fim, gostaria de destacar que esta resenha é um convite para os leitores abraçarem este livro cativante e competente. Uma pesquisa profunda, rigorosa e exemplar foi realizada, por isso merece ser lida e debatida pelo campo educacional. Ressalto ainda que, pelas limitações de uma resenha, alguns elementos importantes desta obra ficaram de fora, principalmente pelo quantitativo de páginas e pela complexidade do debate contido neste volume. Assim, mais um motivo para que todos se debrucem sobre este livro, que, sem sombra de dúvidas, se tornará uma referência para a educação brasileira.

\footnotetext{
${ }^{\text {i }}$ Professor Adjunto da Universidade Federal Fluminense - Ciência Política e Educação.

ii http://www.luizantoniocunha.pro.br/uploads/livros/AEducacaoBrasileiranaPrimeiraOndaLaica.pdf
} 